\title{
Metridium senile: dispersion and small scale colonization by the combined strategy of locomotion and asexual reproduction (laceration)
}

\author{
Martin Wahl \\ Abteilung für marine Systematik und Ókologie, Universität Kiel, Olshausenstraße 40-60, \\ D-2300 Kiel, Federal Republic of Germany
}

\begin{abstract}
The process of biotope occupation by the anenome Metridium senile in the absence of pelagic larvae has been investigated by an in situ monitoring experiment lasting from July 1981 to April 1982. This process is composed of several behavioral phases: dispersion of the anemones on the new substrate by high locomotory activity, colonization of the 'chosen' habitat by intensive asexual reproduction and finally, a stationary phase. One characteristic of the particular ecological situation in the Flensburg fjord (Western Baltic) seems to be the absence in $M$. senile of sexual reproduction and larvae resulting in a mono- or oligoclonality of the Fjord population. This study shows that even if pelagic dispersal is missing, local dispersion and proliferation can be assured by locomotion and laceration.
\end{abstract}

\section{INTRODUCTION}

Metridium senile (anthozoa, cnidaria) is considered a hemisessile organism, which signifies that this anemone, while capable of restricted locomotion, is 'normally' fixed to a hard substratum and stationary. Large scale spreading and gene flow of such a species are generally ensured by a planktonic larval stage (Crisp 1974, 1979). Middle range (ca 0.1 to $10 \mathrm{~km}$ ) dispersal can also be realized by the transport by currents of adult anemones (Shick et al, 1979): the transport of Metridium senile attached to floating objects into or within the Flensburg fjord seems quantitatively unimportant but may have played a part in the first introduction of the ancestors of the Fjord $M$. senile populations. On the other hand, if an anemone lets go of its normally firmly anchored holdfast, it is frequently current-swept into new surroundings. There are 2 known factors that trigger the detachment reaction: predational stress by Aeolidia papillosa (Shick et al. 1979) (this nudibranch is rare or absent in

Present address: Laboratoire Arago, F-66650 Banyuls-surMer, France the Flensburg fjord) and $\mathrm{O}_{2}$ depletion. When the environmental oxygen concentration falls below a critical value, $M$. senile detaches from its substratum and may be drifted along (Wahl 1984, unpubl.). This phenomenon is quite restricted in time and space (summer, deeper areas of the inner fjord) and must have been even more so before anthropogenic input of organic nutrients began to fuel the eutrophication process.

The third and spatially the most limited method of propagation is the combined strategy of locomotion and asexual reproduction (laceration). For small scale occupation and spreading this method is certainly the most efficient (Hoffmann 1976, Shick et al. 1979, Serens 1979).

In the Flensburg fjord larval settlement seems not to occur (see 'Discussion'). Can the quite dense and homogeneous colonization of the fjord be solely due to locomation and laceration (in combination with the occasional drift of adults)? The present in situ study, lasting from July 1981 to April 1982, attempted to evaluate the asexual dispersion potential of Metridium senile. Observations on the (still hypothetical) absence of sexual reproduction and larvae in the Flensburg fjord are also discussed. 


\section{METHODS}

This investigation was carried out by 'Scuba'-diving. The experimental site lay within a densely packed mussel bed ( $8 \mathrm{~m}$ depth, local Metridium senile abundance ca $20 \mathrm{~m}^{-2}$ ) in the inner Flensburg fjord near Kollund, Denmark. A galvanized metal table (Fig. 1)

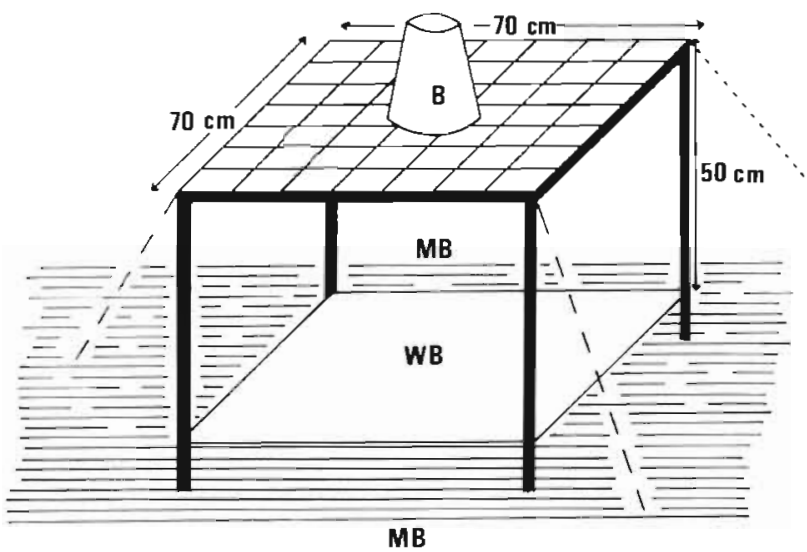

Fig. 1. The experimental set-up as it stood in a mussel bed (MB) at $8 \mathrm{~m}$ depth near Kollond, Denmark. B: overturned basket containing the test anemones prior to start of experiment; WB: wooden board preventing bogging down of the table

was firmly anchored by 4 strong, $1 \mathrm{~m}$ tent pegs. Its $70 \times$ $70 \mathrm{~cm}$ PVC-covered top, which stood some $50 \mathrm{~cm}$ above the sediment surface, was divided by a coordinate system into forty-nine $10 \times 10 \mathrm{~cm}$ squares. On July 10,1981 , I collected 15 adult Metridium senile specimens in the immediate neighborhood of the table, detached them carefully from their Mytilus edulis shells and placed them under an overturned plastic basket (opening diameter $\mathrm{ca} 20 \mathrm{~cm}$ ) in the center of the table-top.

Six d later, 8 anemones had settled on the PVC tabletop; the remainder had attached to and were removed with the basket. On this day, all 8 test anemones were densely grouped within or on the borders of the central square (D4; Fig. 2)

a

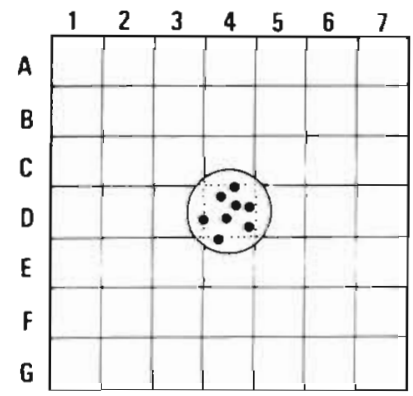

b

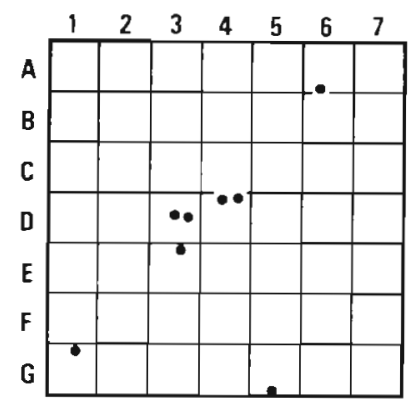

During the following 6 mo I visited the table at least once a week, monitoring the exact position of each anemone, its habitus, the absence, presence and number of laceration offspring and the duration of individual laceration activity. The individual test anemones could be identified by their different sizes, their relative positions and/or slight differences in tentacle color design. I refrained from marking them which would undoubtedly have influenced their behavior.

For each test anemone successive positions were marked on an individual chart (Fig. 3). The interval between succeeding positions is the minimum distance the anemone must have crawled between the 2 monitoring events. It is improbable that the anemones

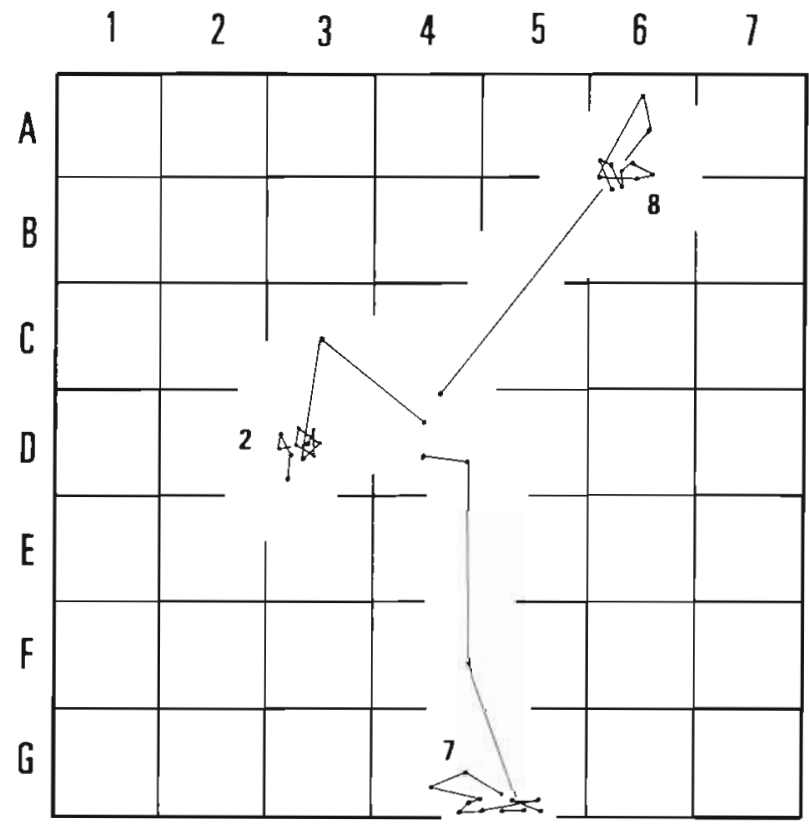

Fig. 3. Superposition of 3 (Nos. 2, 7, 8) of the 8 individual migration charts: the initial migration phase and the laceration phase with small-scale oscillations can easily be dis. cerned. (Some positions in the oscillation zones have been omitted in order to avoid confusion)

Fig. 2. Top view of table showing distribution of anemones. (a) Just before start of experiment: 8 anemones ( $\bullet$ ) fixed in D4. (Circle symbolizes opening circumference of basket.) (b) End of Phase I: the anemones have dispersed. (c) End of Phase II: the adults occupy nearly the same positions as $10 \mathrm{wk}$ before. The offspring ('laceration buds') are symbolized by small dots ( ) 
always moved in a straight line, but any detours could not be detected by this method. I consider that the locomotion performances measured here could easily be multiplied by 2 or 3 without risk of over-estimation.

\section{RESULTS}

As soon as the basket was removed (July 16) the 8 test anemones began to crawl along. Neither the 'speed' (measured minimum distance per monitoring interval) nor the direction of locomotion were the same with all individuals (Fig. $2 \& 3$ ). Some moved 'quickly' to the borders of the table-top whereas others remained within the 4 central squares of the coordinate system during the entire 9 mo of monitoring. In spite of such differential behavior the mean values of distances covered per time span (usually $1 \mathrm{wk}$ ), plotted as a summation graph (Fig. 4), clearly show the succession of 3 different activity phases:

(1) Phase I (mid-July to end of August, ca $6 \mathrm{wk}$ ): dispersion. During this period locomotory activity was greatest. The average 'speed' lay between 5 and $8 \mathrm{~cm}$ $\mathrm{wk}^{-1}$. Some individuals covered more than $20 \mathrm{~cm}$ in $7 \mathrm{~d}$. (Bear in mind that these are net values; the distance actually covered may have been much greater.)

Toward the end of this phase the average distance between any 2 anemones had reached $30.5 \mathrm{~cm}( \pm$ $17.7)$, whereas it had been $5.9 \mathrm{~cm}( \pm 2.3)$ only $6 \mathrm{wk}$ before (Table I). Through this dispersion by a factor of 5 the anemones now occupied a much greater territory than at the start of the experiment (Fig. 2A, B; see 'Discussion')

(2) Phase II (beginning of September until midNovember, ca $10 \mathrm{wk}$ ): laceration. After $6 \mathrm{wk}$ of dispersion the locomotory activity of the test Metridium
Table 1. Distances between test anemones at the beginning (lower left) and end (upper right) of Phase I. The effects of dispersion are evident: the mean distance between any 2 individuals $(\bar{x})$ has increased by a factor of 5

\begin{tabular}{|c|c|c|c|c|c|c|c|c|c|}
\hline $\mathbf{N}^{\mathbf{0}}$ & 1 & 2 & 3 & 4 & 5 & 6 & 7 & 8 & \multirow{9}{*}{$\begin{array}{l}\text { End of } \\
\text { locomotory } \\
\text { phase } \\
\text { (od }: 30.5 \mathrm{~cm} \text { ) }\end{array}$} \\
\hline 1 & 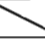 & 42 & 41 & 50 & 52 & 38 & 43 & 80 & \\
\hline 2 & 5 & $\gamma$ & 3 & 10 & 18 & 6 & 34 & 39 & \\
\hline 3 & 9 & 7 & $\gamma$ & 10 & 17 & 4 & 32 & 40 & \\
\hline 4 & 9 & 9 & 4 & $\gamma$ & 15 & 13 & 37 & 30 & \\
\hline 5 & 9 & 11 & 8 & 5 & 7 & 17 & 25 & 32 & \\
\hline 6 & 6 & 8 & 8 & 6 & 3 & 7 & 28 & 43 & \\
\hline \begin{tabular}{|l|}
7 \\
\end{tabular} & 5 & 4 & 4 & 5 & 6 & 4 & 7 & 56 & \\
\hline 8 & 7 & 7 & 4 & 3 & 3 & 3 & 3 & 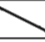 & \\
\hline
\end{tabular}

senile dropped abruptly to about $1 / 5$ of their former performances (Fig. 4). From now on the anemones confined themselves to small-scale oscillations within a mean area of $50 \mathrm{~cm}^{2}$ (Fig. 3). Some days later the first small laceration buds could be detected, thus explaining this new behavioral pattern. Asexual reproduction in $M$. senile is always coupled with small locomotory steps: a border segment of the pedal disc is firmly glued to the substratum, then the adult crawls off in the opposite direction provoking a tearing of the tissue and separation of the anchored segment. Usually, this fragment then breaks up into several small pieces of approximately 1 to $5 \mathrm{~mm}$ diameter. (The further development of the buds has been described in detail by Torrey [1898], Hahn [1905], Chia [1976] and Wahl [1982]). The adult moves off a few $\mathrm{cm}$ and may begin another laceration step, thus leaving its offspring in the wake of its erratic course.

At the age of 2 to $3 \mathrm{wk}$ the young anemones, too, began to show first locomotory activity. As identification of these small individuals was impossible, their migrations could not be monitored.
Fig. 4. Summation graph of mean locomotory activity and a representation of individual laceration activity. The 3 phases are visible. The short segment with a steeper slope within Phase II coincides with maximum laceration activity

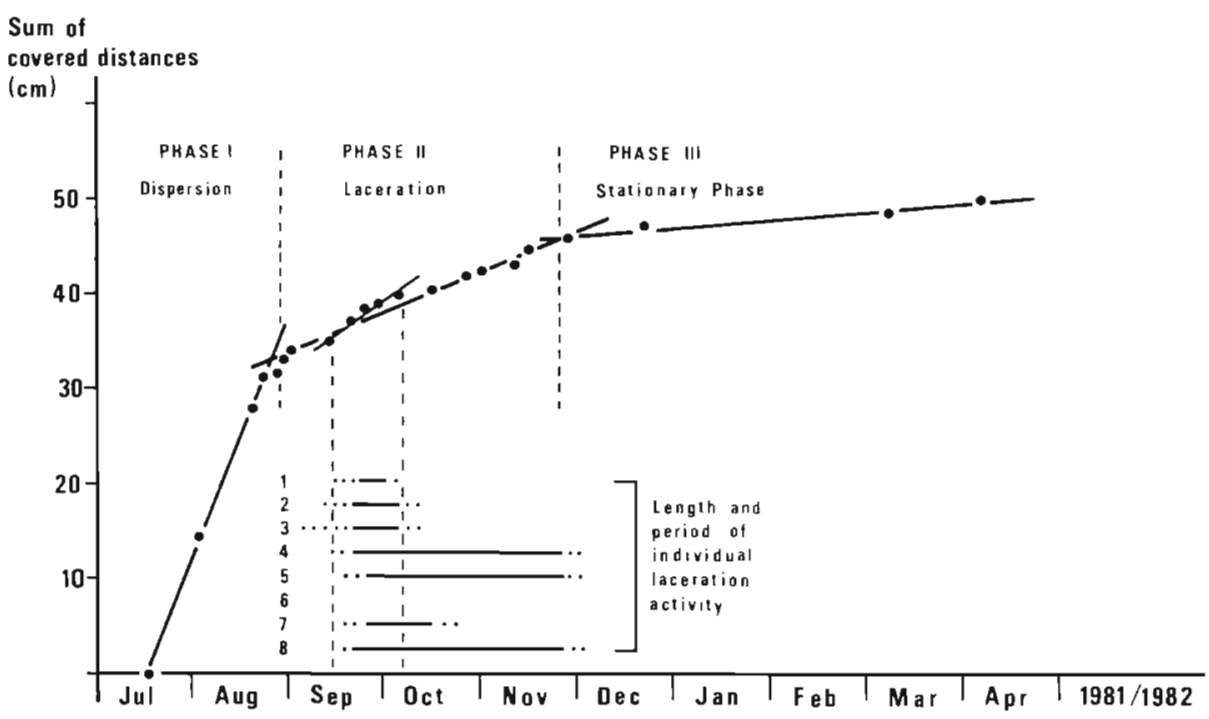


The laceration phase was not altogether synchronous and of the same duration for the different individuals (Fig. 4). A closer analysis of the laceration part of the summation graph reveals a $3 \mathrm{wk}$ long segment with a slightly steeper slope than average. This segment coincides with the period where the maximum number (7) of test anemones were lacerating. (One anemone, No, 6, did not reproduce during the observation period.) This seems to confirm the diving observation that locomotion during Phase II is closely linked to asexual reproduction.

The anemone distribution on the table-top at the end of the laceration period is shown in Fig. 2C. At this stage the anemone abundance on the new substratum had reached its maximum: ca 50 individuals per $0.5 \mathrm{~m}^{2}$. During the following months more than $50 \%$ of the laceration offspring disappeared. A final count could not be made because the experimental set-up was destroyed by a ship's mussel dredge before the projected end of the experiment.

(3) Phase III (end of November until end of experiment, ca $20 \mathrm{wk}$ ): stationary phase. When all laceration activity had ceased in mid-November, the adult Metridium senile finally became stationary. On April 4 the anemones occupied practically the same positions as they had more than 4 mo earlier. The slight slope of the graph in Phase III (Fig. 4), suggesting slow locomotion, while in fact the anemones hardly shifted position, is probably an artefact caused by the uncertainty margin of the measurements $( \pm 1 \mathrm{~cm})$. The precision of measuring was much greater during Phase II when the location of an adult could be determined quite accurately by the position of young laceration buds that do not move during the first few weeks.

\section{DISCUSSION}

The present paper describes the occupation by Metridium senile of newly available space (though of restricted dimensions and artificial nature in this study) by the sole means of locomotion and asexual reproduction. This strategy seems to be quite efficient (compare Fig. 2A \& 2C).

\section{The 3 behavioral phases}

(1) Intensive locomotory activity with rapid dispersal of the anemones. It cannot be decided here whether this behavior is inherent or if it was stimulated by the initial high 'population density' (Fig. 2A).

(2) Asexual reproduction resulting in a rapid numerical increase of the 'table top population' and small scale oscillations of the adult. According to several authors (Hoffmann 1976, Serens 1979, Shick et al. 1979) laceration in Metridium senile may serve several purposes: (i) regulation of body size to hydrodynamically best values for given local current conditions,(ii) numerical multiplication of a locally successful genotype, and/or (iii) colonization of a newly occupied substratum. In this experiment, all aspects may have played a part in the stimulation of laceration: raising the anemones from their sediment-close habitat ( 5 to $10 \mathrm{~cm}$ above sediment surface) onto the table top (height $50 \mathrm{~cm}$ ) may have exposed them to stronger mean current velocities (Walger 1964, Wainwright \& Koehl 1976, Koehl 1977 a, b). However the fact that laceration activity was general and not restricted to, or more intensive with, the taller individuals, and that it first occurred 2 mo after the transfer seems to emphasize, at least for the given circumstances, the importance of the last 2 points (cloning and colonization). It also suggests that this behavior may be inherent in this species (dispersal in the presence of newly available space): neither a simultaneous general laceration activity of other anemones in the nearby neighborhood was observed, nor could changes in external factors (salinity, temperature etc.) be linked causally to variations in the behavioral pattern of the anemones (see below).

(3) During the last phase the adults became stationary. This change of activity seemed not to be caused by a loss of vitality or the influence of adverse factors Figuratively expressed, their activity was reduced to 'holding the field' against occupation by other sessile organisms. The offspring continued to crawl about with a general tendency to disperse.

\section{Influence of external factors}

Fig. 5 shows the variations of oxygen concentration, particle density (represented by its inverse: Secchidepth), salinity and temperature during the monitoring period. It is clear that at least the first 3 parameters cannot be responsible for the behavior of Metridium senile (correlation coefficients and Spearman's Rank Correlation coefficients: $r\left(\mathrm{O}_{2}\right)=-0.3, \mathrm{r}_{\mathrm{s}}\left(\mathrm{O}_{2}\right)=-0.34$; $r(\mathrm{Sec})=-0.45,. \mathrm{r}_{\mathrm{s}}(\mathrm{Sec})=.-0.37 ; \mathrm{r}(\% \mathrm{o})=+0.15, \mathrm{r}_{\mathrm{s}}(\% \mathrm{o})$ $=+0.33$; as calculated for the pairs: external factors vs mean distance covered $\mathrm{d}^{-1} ; \mathrm{n}=20$ in each case). A causal link between water temperature and locomotory activity does not seem likely in view of the facts that (i) the abrupt slowing-down of locomotory activity at the end of August coincides with highest water temperatures, and (ii) the temperature decline from 17 to $4^{\circ} \mathrm{C}$ between September and December did not noticeably reduce locomotory activity. Even if statistical analysis does not completely exclude correlation 
Fig. 5. Variations of environmental parameters during the monitoring period (taken $<50 \mathrm{~m}$ from the experimental table at $1 \mathrm{~m}$ depth). (a) Oxygen $\left(\mathrm{O}_{2} ; \mathbf{v}\right)$ and Secchi-depth $(\mathrm{S} ; \mathrm{O})$ (Lacking direct measurements of zooplankton abundance, the Secchi-depth, being inversely related to the density of suspended particles, may give a rough idea of food availability.) (b) Salinity $(\mathrm{S} \% ; \bullet)$ and temperature $\left(\mathrm{T}^{\circ} ; \mathbf{m}\right)$ (Data by courtesy of Dr C Valentin)
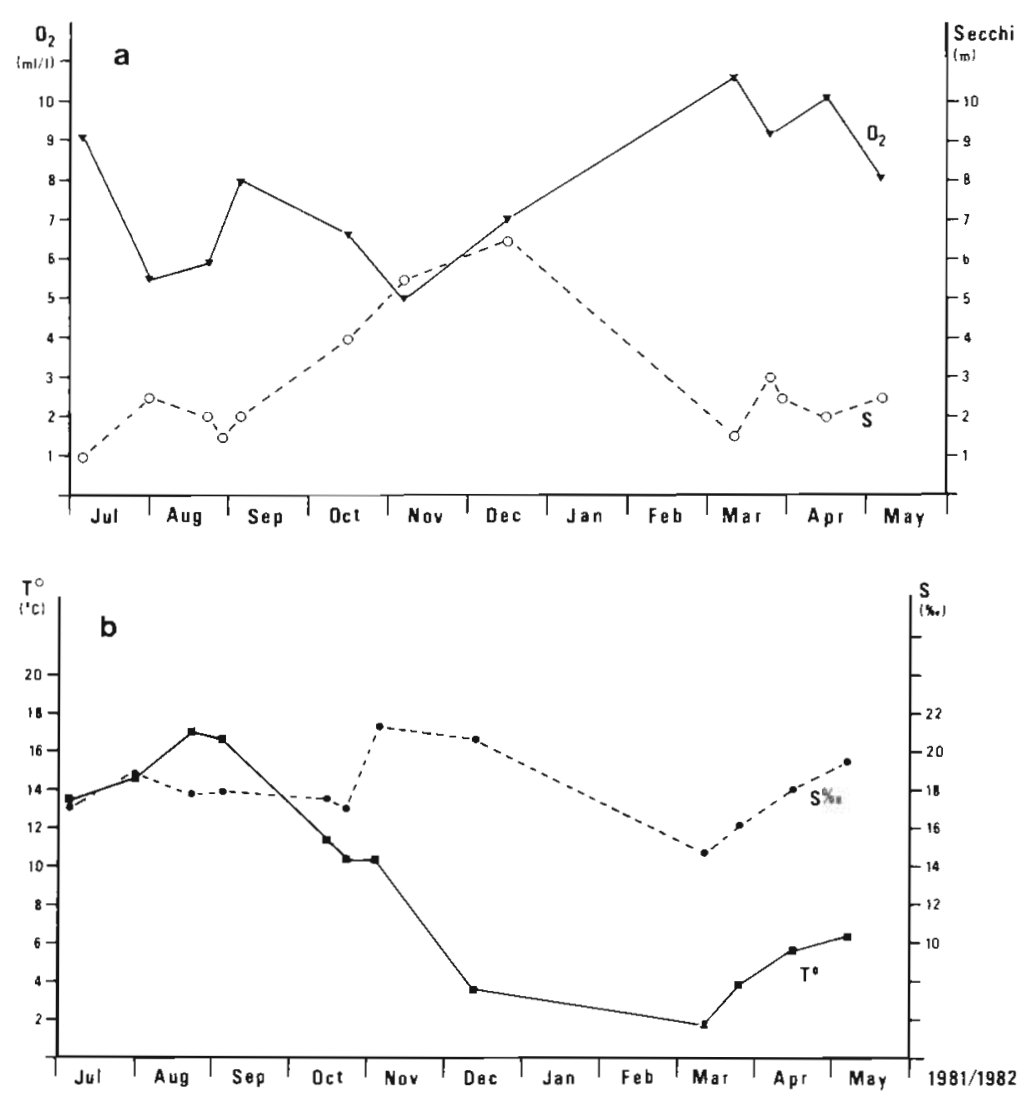

between locomotory activity and ambient temperature, the link cannot be very close $\left[\mathrm{r}\left(\mathrm{T}^{\circ}\right)=+0.49, \mathrm{r}_{\mathrm{s}}\left(\mathrm{T}^{\circ}\right)=\right.$ +0.53 , linear regression coefficient $r_{1}=+0.24, \mathrm{n}=$ 20].

With regard to the possible influence of other fouling organisms, the settlement and development of other epizoans on the table have, for methodological reasons, been assessed only qualitatively. An initial Polydora sp. population was replaced by mid-August by a quite homogenous lawn consisting of small algae and hydrozoans (Campanularia verticillata). An abrupt qualitative or quantitative change in this fouling community coinciding with, and possibly responsible for, the decline in locomotory activity (end of August) has not been observed. Thus an external influence controlling the observed behavioral pattern of locomotion and laceration has not been detected. It is tempting to conclude that the behavioral pattern described is independent of these external, seasonally varying factors (except perhaps the availability of food which has not been assessed directly). However, the experiment should be repeated in a constant physical environment to demonstrate whether the observed behavioral sequence really is a typical Metridium senile strategy for small-scale dispersal.

In conclusion, Metridium senile seems to be quite capable of colonizing an adjacent unoccupied area by locomotion and laceration only - a faculty that could prove essential in a region where larval dispersal may be lacking, as will be discussed below.

\section{Absence of sexual reproduction and pelagic larvae}

During 3 yr of regular diving monitoring of the Fjord's Metridium senile population(s), and even with the help of in situ experiments especially designed to this end (unpubl.), I have not once observed larval settlement in this area, which by its low salinity (18 to $22 \%$ ) certainly represents a 'frontier-biotope' for this marine species. $M$. senile larvae seem not to be present in the Baltic plankton (Ackefors 1969, Hillebrand 1972 , Lenz 1974, Henroth \& Ackefors 1979).

There are other indications for the scarcity or absence of sexual reproduction of these anemones in the Flensburg fjord, and that its Metridium senile fauna may consist of oligoclonal populations or even of 1 monoclonal population. (1) The Fjord anemones, like Baltic $M$. senile in general (Möbius 1873), are all of the same colour: brown, which moreover is one of the less frequent colour variations described for $M$. senile (Fox \& Pantin 1940, Hand 1955, Hoffmann 1976). In the North Sea, the probable origin of the Baltic $M$. senile fauna, the most frequent phenotype is white, followed 
by red, then brown and lemon yellow (Fox \& Pantin 1940). (2) Purcell (1977) has described the ready development of 'catch tentacles' by Pacific $M$. senile whenever they are stimulated by repeated contact with a genetically different specimen of the same species. Kaplan (1983) confirms the common occurrence of catch tentacles in fluffy sea anemone populations but adds that intraspecific aggression is restricted to situations where genetically different individuals of the same sex are in contact distance. In the Flensburg Fjord I have never been able to discover this defense reaction, neither in densely packed populations where frequent tentacle contact was inevitable, nor in aquarium experiments with individuals collected throughout the Fjord. (3) An imported batch of the frequent white North Sea $M$. senile could not be adapted to Flensburg Fjord salinity $(20 \%)$, even if the transition process was extremely gradual $\left(0.1 \% \mathrm{~h}^{-1}\right.$; Wahl unpubl.). It might be that the salinity difference blocks the immigration of adult members of other $M$. senile populations (less pre-adapted than the local 'brown') and larvae from the North Sea into the Baltic Sea. For many species it is known that the larvae are much less tolerant to salinity-stress than the adult form (Innes \& Haley 1977, Young \& Hazlett 1978, Kuhl \& Oglesby 1979, Berry \& Hunt 1980).

The suspicion that the Flensburg fjord Metridium senile population is oligo- or even monoclonal needs to be tested by biochemical analyses (e.g. phosphohexose-isomerase phenotype, Hoffmann 1976).

If sexual reproduction and larvae prove to be absent in the Western Baltic Metridium senile population, genetic renewal and variation by recombination and geneflow should be severely limited. The continuous asexual reproduction of the 'brown' genotype(s) that has been successful in this particular environment can according to Williams (1964, as cited in Hoffmann 1976), be likened to the multiplication of a lottery ticket that has proved a winner, and will remain oneas long as conditions do not change: the genetical adaptive flexibility sensu Grassle (1967, as cited by Sanders 1968) of a monoclonal population is probably quite reduced.

As to the consequences of the (hypothetical) lack of pelagic larvae for dispersion, in combination with the current-transport of detached adult anemones over a range of $\mathrm{km}$, the locomotion/laceration strategy should be efficient enough to account for the widespread and quite homogeneous occurrence of Metridium senile in the Western Baltic - even if pelagic larvae are lacking

Acknowledgements. I am grateful to Prof. Dr W. Noodt (Kiel University) for his competent and kind supervision of this program.

\section{LITERATURE CITED}

Ackefors, H. (1969). Ecological zooplankton investigations in the Baltic proper 1963-1965. Fish. Bd Sweden, Inst. Mar Res., Ser. Biol., Rep. no. 18

Berry, A. J., Hunt, D. C. (1980). Behaviour and tolerance of salinity and temperature in new-born Littorina rudis (Maton) and the range of the species in the Forth estuary. J. mollusc. Stud. 46 (1): 55-65

Chia, F.-S. (1976). Sea anemone reproduction: patterns and adaptive radiation. In: Mackie, G. O. (ed.) Coelenterate ecology and behavior, Plenum Press, New York, p 261-270

Crisp, D. J. (1974). Factors influencing the settlement of marine invertebrate larvae. In: Grant, P. T., Mackie, A. M. (ed.) Chemoreception in marine organisms. Academic Press, London, New York, p. 177-266

Crisp, D. J. (1979). Disperal and reaggregation in sessile marine invertebrates, paricularly barnacles. In: Larwood G., Rosen, B. R. (ed.) Biology and systematic of colonial organisms. Academic Press, London, New York, $p$ 319-327

Fox, D. L., Pantin, C. F. A. (1940). The colours of the plumose anemone Metridium senile. Phil. Trans. R. Soc. Ser. B 230 $415-449$

Hahn, C. W (1905). Dimorphism and regeneration in Metridium marginatum (Milne-Edwards). J. exp. Zool. 2 225-235

Hand, C. (1955). The sea anemones of central California, Part III: the acontiarian anemones. Wasman J. Biol. 13 (2). 189-251

Henroth, L., Ackefors, H. (1979). The zooplankton of the Baltic proper. Fish. Bd Sweden. Inst. Mar. Res. Ser. Biol., Rep. no. 2

Hillebrand, M. (1972). Untersuchungen über die qualitative und quantitative Zusammensetzung des Zooplanktons in der Kieler Bucht. Dissertation, Univ. of Kiel

Hoffmann, R. J. (1976). Genetics and asexual reproduction of the sea anemone Metridium senile. Biol. Bull. mar. biol. Lab., Woods Hole 151: 478-488

Innes, D. J., Haley, L. E. (1977). Genetic aspects of larval growth under reduced salinity in Mytilus edulis. Biol. Bull. mar. biol. Lab., Woods Hole 153 (2): 312-321

Kaplan, S. W. (1983). Intrasexual aggression in Metridium senile. Biol. Bull. mar. biol. Lab., Woods Hole 165: 416-418

Koehl, M. A. R. (1977a). Effects of the sea anemones on the flow forces they encounter. J. exp. Biol. 69: 87-105

Koehl, M. A. R. (1977b). Mechanical organization of cantiliver-like sessile organisms: sea anemones. J. exp. Biol. 69: $127-142$

Kuhl, D. L., Oglesby, L. C. (1979). Reproduction and survival of the pile worm Nereis succinea in higher Salton Sea salinities. Biol. Bull. mar. biol. Lab., Woods Hole 157 (1): 153-165

Lenz, J. (1974). Untersuchungen zum Nahrungsgefüge im Pelagial der Kieler Bucht. Thesis, Inst. Meereskunde Kiel

Möbius, K. (1873). Die wirbellosen Tiere der Ostsee. Jahresber. Commn. Wiss. Unters. Dt. Meere, Kiel 1: 97-144

Purcell, J. E. (1977) Aggressive function and induced development of catch-tentacles in the sea anemone Metridium senile (Coelentaria, Actiniaria). Biol. Bull. mar biol. Lab., Woods Hole 153: 355-368

Sanders, H. L. (1968). Marine benthic diversity: a comparative study. Am. Nat. 102 (925): 243-282

Serens, K. P. (1979). The energetics of asexual reproduction 
and colony formation in benthic marine invertebrates. Am. Zool. 19: 683-697

Shick, J. M., Hoffmann, R. J., Lamb, A. N. (1979). Asexual reproduction, population structure and genotype environment in sea anemones. Am. Zool. 19: 699-713

Torrey, H. B. (1898). Observations on monogenesis in Metridium. Proc. Calif. Acad. Sci., Ser. III Zool. 1 (10): 345-360

Wahl, M. (1982). In situ Versuche zum Vorkommen von Metridium senile in der Flensburger Förde. Diplomarbeit, Univ. Kiel

Wahl, M. (1984). The fluffy sea anemone Metridium senile in periodically oxygen-depleted surroundings. Mar. Biol. 81: $81-86$
Wahl, M. (1985). The recolonization potential of Metridium senile in an area previously de-populated by oxygen deficiency. Oecologia (Berl.) (in press)

Wainwright, S. A., Koehl, M. A. R. (1976). The nature of flow and the reaction of benthic cnidaria to it. In: Mackie, $G$. O (ed.) Coelenterate ecology and behavior. Plenum Press New York, p. 5-21

Walger, E. (1964). Zur Darstellung von Korngrößenverteilungen. Geol. Rundsch. 54: 976-1002

Young, A. M., Hazlett, T L. (1978). The effect of salinity and temperature on the larval development of Clibanarius vittatus (Bosc) (Crustacea: Decapoda: Diogenidae). J. exp. mar. Biol. Ecol. 34 (2): 131-141

This paper was submitted to the editor; it was accepted for printing on August 5, 1985 